\title{
In silico exploration of Red Sea Bacillus genomes for natural product biosynthetic gene clusters
}

\author{
Ghofran Othoum 1 , Salim Bougouffa', Rozaimi Razali', Ameerah Bokhari', Soha Alamoudi ${ }^{3}$, André Antunes ${ }^{4}$, \\ Xin Gao', Robert Hoehndorf', Stefan T. Arold', Takashi Gojobori ${ }^{1,2}$, Heribert Hirt², Ivan Mijakovic ${ }^{5,6}$, \\ Vladimir B. Bajic ${ }^{1}$, Feras F. Lafi ${ }^{1,7}$ and Magbubah Essack ${ }^{1 *}$ (I)
}

\begin{abstract}
Background: The increasing spectrum of multidrug-resistant bacteria is a major global public health concern, necessitating discovery of novel antimicrobial agents. Here, members of the genus Bacillus are investigated as a potentially attractive source of novel antibiotics due to their broad spectrum of antimicrobial activities. We specifically focus on a computational analysis of the distinctive biosynthetic potential of Bacillus paralicheniformis strains isolated from the Red Sea, an ecosystem exposed to adverse, highly saline and hot conditions.

Results: We report the complete circular and annotated genomes of two Red Sea strains, B. paralicheniformis Bac48 isolated from mangrove mud and B. paralicheniformis Bac84 isolated from microbial mat collected from Rabigh Harbor Lagoon in Saudi Arabia. Comparing the genomes of B. paralicheniformis Bac48 and B. paralicheniformis Bac84 with nine publicly available complete genomes of $B$. licheniformis and three genomes of B. paralicheniformis, revealed that all of the B. paralicheniformis strains in this study are more enriched in nonribosomal peptides (NRPs). We further report the first computationally identified trans-acyltransferase (trans-AT) nonribosomal peptide synthetase/ polyketide synthase (PKS/ NRPS) cluster in strains of this species.

Conclusions: $B$. paralicheniformis species have more genes associated with biosynthesis of antimicrobial bioactive compounds than other previously characterized species of $B$. licheniformis, which suggests that these species are better potential sources for novel antibiotics. Moreover, the genome of the Red Sea strain B. paralicheniformis Bac48 is more enriched in modular PKS genes compared to B. licheniformis strains and other B. paralicheniformis strains. This may be linked to adaptations that strains surviving in the Red Sea underwent to survive in the relatively hot and saline ecosystems.
\end{abstract}

Keywords: Bacillus licheniformis, Bacillus paralicheniformis, Antimicrobials, Biosynthetic gene clusters, Genome-mining, Nonribosomal peptides, Polyketides, Bacteriocins, Lanthipeptides, Bioinformatics

\section{Background}

Bacillus licheniformis is a Gram-positive facultative anaerobe, dubbed an industrial workhorse due to its use in several fields of biotechnology and its ability to secrete large amounts of commercially-used biomolecules and enzymes $[1,2]$. These include specialty chemicals (e.g., citric acid and poly- $\gamma$-glutamic acids) and enzymes

\footnotetext{
* Correspondence: magbubah.essack@kaust.edu.sa

${ }^{1}$ Computational Bioscience Research Center (CBRC), King Abdullah University of Science and Technology (KAUST), Thuwal 23955-6900, Kingdom of Saudi Arabia

Full list of author information is available at the end of the article
}

(e.g., proteases and $\alpha$-amylases used in the food, detergent, textile and paper industries) [3-6]. Most importantly, the antimicrobial capabilities of $B$. licheniformis have been widely reported [7-11] and several $B$. licheniformis strains have been used as biocontrol agents [12-15] (e.g., EcoGuard). Moreover, B. licheniformis strains are used in the petroleum industry for microbially enhanced oil recovery $[7,16]$ due to their ability to produce lipopeptide biosurfactants.

(C) The Author(s). 2018 Open Access This article is distributed under the terms of the Creative Commons Attribution 4.0 International License (http://creativecommons.org/licenses/by/4.0/), which permits unrestricted use, distribution, and reproduction in any medium, provided you give appropriate credit to the original author(s) and the source, provide a link to the Creative Commons license, and indicate if changes were made. The Creative Commons Public Domain Dedication waiver (http://creativecommons.org/publicdomain/zero/1.0/) applies to the data made available in this article, unless otherwise stated. 
B. paralicheniformis is a recently described new species within the Bacillus genus [17]. Despite the phylogenetic proximity to $B$. licheniformis that suggests biotechnological relevance, this species remains largely unexplored. The first description of $B$. paralicheniformis showed that it displayed a wider range of antimicrobial capabilities than $B$. licheniformis, despite being unable to produce lichenicidin or bacteriocins as does B. licheniformis [18].

A genomic-scale comparison of strains in both species can provide insights into their potential metabolic processes, their biosynthetic capabilities, and their stress adaptations. The evaluation of these properties helps to identify potential industrially relevant strains with novel and/or improved production capabilities of desired compounds [19-22]. One way of assessing the production capabilities of these strains is through the identification of gene clusters that are co-localized in the genome [23]. These biosynthetic gene clusters (BGCs) include nonribosomal peptide synthetases (NRPSs), polyketide synthases (PKSs), and ribosomally synthesized and post-translationally modified peptides (RiPPs) [24].

Ecologically, strains of B. licheniformis and B. paralicheniformis inhabit diverse environments including marine, freshwater, and food-related niches. This diversification in ecological, and phenotypic properties has led B. licheniformis to become one of the most studied Bacillus species. Reason being, Bacillus strains such as these that are adapted to survive in high osmolarity environments, and have metabolic capacities similar to industrial strains are highly desirable. As in industrial settings, strains are often challenged with increased external osmolarity due to the high-level secretion of metabolites into the growth medium, threatening their productivity, and/or viability [25-27].

An environment that should be explored for such resilient, productive Bacillus strains is the Red Sea that exhibits relatively high salinity (36-41 p.s.u), and temperature $\left(24{ }^{\circ} \mathrm{C}\right.$ in spring, and up to $35{ }^{\circ} \mathrm{C}$ in summer) [28]. It is expected that strains from this environment are able to produce a number of thermo-tolerant enzymes, as well as provide robust microbial cell factories that are able to survive frequent exposure to high salinity and high temperature, and produce sturdier enzymes that might be better suited for industrial applications [29].

In this study, we sequenced and assembled genomes of two Bacillus strains, B. paralicheniformis Bac 48 and B. paralicheniformis Bac84, both isolated from the Rabigh Harbor Lagoon of the Red Sea in Saudi Arabia. The reason for this selection has been that we previously reported that antimicrobial activity exhibited by $B$. paralicheniformis Bac84 is more pronounced than B. paralicheniformis Bac48, against three-indicator pathogens:
Staphylococcus aureus, Salmonella typhimurium, and Pseudomonas syringae [30]. In the current study we aimed at studying the relevant differences between these two species in more details. Specifically, we estimated the biosynthetic potential of the two Red Sea strains, along with nine B. licheniformis and three B. paralicheniformis strains. By grouping identified BGCs into families of gene clusters using genomic similarity, we highlighted the overall unexplored biosynthetic potential of strains from both groups. We further showed the unique presence of putative antimicrobial clusters in the Red Sea strains, focusing on one uniquely structured hybrid PKS/NRPS cluster that was identified in the genome of the B. paralicheniformis Bac 48 .

\section{Results}

Features of the genomes of the Red Sea Bacillus strains Sequencing the genomes of the Red Sea strains using the SMRT (single molecule real-time) sequencing platform produced 138,867 subreads with a mean length of 9586 bp (298× genome coverage) for $B$. paralicheniformis Bac48 and 108,978 subreads with a mean length of 10,964 bp (273× genome coverage) for B. paralicheniformis Bac84 (Additional file 1: Table S1 and Table S2). The assembly produced a single circular chromosome without plasmids for both strains. B. paralicheniformis Bac48's circular chromosome is $4,464,381$ bp in length containing 4366 predicted open reading frames (ORFs); $51.5 \%$ of the genes are on the positive strand, and $48.5 \%$ are on the negative one. B. paralicheniformis Bac84's circular chromosome is 4376,831 bp in length containing 4306 predicted ORFs; $47.8 \%$ of genes are on the positive strand and $52.2 \%$ are on the negative one. Both genomes have 24 rRNAs and 81 tRNAs genes (Table 1 ).

Genomic island (GI) prediction identified five GIs in B. paralicheniformis Bac48 that include three unique regions (totaling $64.3 \mathrm{~Kb}$ and representing $1.4 \%$ of the genome) and 14 GIs in B. paralicheniformis Bac84 (totaling $142.8 \mathrm{~Kb}$ and representing $3.3 \%$ of the genome) (Fig. 1, Additional file 1: Table S3). Analysis of prophage sequences in the genome revealed three prophage regions in B. paralicheniformis Bac48 (124 genes), with one of them partially overlapping with a GI. Similar analysis in B. paralicheniformis Bac84 also identified three prophage regions (121 genes), with two of them partially overlapping with GIs as well (Fig. 1, Additional file 1: Table S4). When compared with the complete genome, the percentage of the genome that constitutes prophages is $2.4 \%$ for $B$. paralicheniformis Bac 48 and $2.6 \%$ for $B$. paralicheniformis Bac84.

These values suggest a reduced number of horizontally transferred elements, and are comparably lower than values in genomes of other industrially important strains such as B. licheniformis DSM 13 (where GIs represent $4.8 \%$ and prophages represent $6.2 \%$ of the genome). This 
Table 1 Summary of the genomes and annotation of nine B. licheniformis and five B. paralicheniformis strains

\begin{tabular}{|c|c|c|c|c|c|c|c|c|c|c|c|}
\hline Strain & $\begin{array}{l}\text { GenBank } \\
\text { accession } \\
\text { number }\end{array}$ & $\begin{array}{l}\text { Genome } \\
\text { size }(M b)\end{array}$ & $\begin{array}{l}\mathrm{N}^{\circ} \\
\text { contigs }\end{array}$ & $\begin{array}{l}N^{\circ} \\
\text { ORFs }\end{array}$ & $\begin{array}{l}N^{\circ} \text { rRNA genes } \\
(5 S, 16 S, 23 S)\end{array}$ & $\begin{array}{l}N^{\circ} \text { tRNA } \\
\text { genes }\end{array}$ & $\begin{array}{l}\text { GC } \\
\text { content } \%\end{array}$ & $\begin{array}{l}\text { Genomic } \\
\text { islands\% }\end{array}$ & Prophage\% & Environment & Ref. \\
\hline $\begin{array}{l}\text { B. } \\
\text { paralicheniformis } \\
\text { Bac48 }\end{array}$ & CP023666 & 4.46 & 1 & 4366 & 24 & 81 & 45.87 & 1.4 & 2.4 & Mangrove mud & - \\
\hline $\begin{array}{l}\text { B. } \\
\text { paralicheniformis } \\
\text { Bac84 }\end{array}$ & СР023665 & 4.38 & 1 & 4306 & 24 & 81 & 45.84 & 3.3 & 2.2 & Microbial mat & - \\
\hline $\begin{array}{l}\text { B. licheniformis } \\
\text { DSM13 }\end{array}$ & AE017333.1 & 4.22 & 1 & 4256 & 21 & 72 & 46.19 & 4.8 & 6.2 & N/A & [2] \\
\hline $\begin{array}{l}\text { B. licheniformis } \\
\text { HRBL-15TD }\end{array}$ & СР014781.1 & 4.25 & 1 & 4293 & 24 & 81 & 45.92 & 5.8 & 3.6 & Fermented food & - \\
\hline $\begin{array}{l}\text { B. licheniformis } \\
\text { WX-02 }\end{array}$ & СР012110.1 & 4.29 & 1 & 4343 & 24 & 79 & 46.1 & 6.6 & 4.4 & $\begin{array}{l}\text { Soil from Salt } \\
\text { Mine }\end{array}$ & [74] \\
\hline $\begin{array}{l}\text { B. licheniformis } \\
\text { BL1202 }\end{array}$ & СР017247.1 & 4.42 & 1 & 4533 & 24 & 81 & 46 & 9 & 7.6 & Soybean paste & - \\
\hline $\begin{array}{l}\text { B. licheniformis } \\
\text { SCK B11 }\end{array}$ & СР014795.1 & 4.3 & 1 & 4372 & 24 & 81 & 45.93 & 6.2 & 6 & $\begin{array}{l}\text { Korean soybean } \\
\text { paste }\end{array}$ & - \\
\hline \multirow{2}{*}{$\begin{array}{l}\text { B. Licheniformis } \\
\text { SCDB } 14\end{array}$} & CP014842. $1^{\mathrm{a}}$ & \multirow[t]{2}{*}{4.34} & \multirow[t]{2}{*}{2} & \multirow[t]{2}{*}{4369} & \multirow[t]{2}{*}{24} & \multirow[t]{2}{*}{83} & \multirow[t]{2}{*}{46.27} & \multirow[t]{2}{*}{3.5} & \multirow[t]{2}{*}{2.9} & \multirow{2}{*}{$\begin{array}{l}\text { Korean soybean } \\
\text { paste }\end{array}$} & \multirow[t]{2}{*}{-} \\
\hline & CP014843.1 b & & & & & & & & & & \\
\hline $\begin{array}{l}\text { B. licheniformis } \\
\text { SCDB } 34\end{array}$ & СР014793.1 & 4.48 & 1 & 4612 & 24 & 81 & 45.69 & 12.2 & 7.9 & $\begin{array}{l}\text { Korean soybean } \\
\text { paste }\end{array}$ & - \\
\hline $\begin{array}{l}\text { B. licheniformis } \\
\text { SCCB } 37\end{array}$ & СР014794.1 & 4.4 & 1 & 4496 & 24 & 81 & 45.96 & 10 & 8 & $\begin{array}{l}\text { Korean soybean } \\
\text { paste }\end{array}$ & - \\
\hline $\begin{array}{l}\text { B. licheniformis } \\
\text { YNP1-TSU }\end{array}$ & CM007615.1 & 4.28 & 10 & 4376 & 6 & 65 & 45.87 & 5.7 & 4.8 & Hot spring & [75] \\
\hline $\begin{array}{l}\text { B. } \\
\text { paralicheniformis } \\
\text { ATCC } 9945 \text { a }\end{array}$ & СР005965.1 & 4.38 & 1 & 4392 & 21 & 72 & 45.9 & 4.8 & 1.9 & Soil & [76] \\
\hline $\begin{array}{l}\text { B. } \\
\text { paralicheniformis } \\
\text { BL-09 }\end{array}$ & СР010524.1 & 4.39 & 1 & 4421 & 21 & 72 & 45.9 & 2.3 & 3 & $\begin{array}{l}\text { Natural } \\
\text { fermented sour } \\
\text { congee }\end{array}$ & - \\
\hline $\begin{array}{l}\text { B. } \\
\text { paralicheniformis } \\
\text { MDJK30 }\end{array}$ & СР020352.1 & 4.35 & 1 & 4363 & 24 & 81 & 45.9 & 2.1 & 1.6 & Rhizosphere & - \\
\hline
\end{tabular}

${ }^{a}$ Chromosome

bPlasmid

paucity of horizontal gene transfer in B. paralicheniformis Bac48 and B. paralicheniformis Bac84 genomes is an advantage, as removing GIs and prophages is a necessary step for stabilizing minimized genomes and for streamlining metabolism in biotechnological hosts [31].

\section{Phylogenetic positioning of the Red Sea Bacillus strains}

For a comprehensive comparative analysis of the genomes and to ascertain the phylogenetic position of Bac48 and Bac84 within the Bacillus genus, a phylogenetic tree was generated using 494 orthogroups (Fig. 2). According to Wang and Ash [32], phylogenetic trees of Bacillus that use this approach are more in line with results from the whole genome feature frequency profiling and are more accurate than phylogenetic trees based on single marker genes such 16S rRNA, gryB (gyrase subunit B) or aroE (shikimate-5-dehydrogenase) genes.
Other than the two Red Sea strains, our phylogenetic analysis included ten $B$. licheniformis strains, three $B$. paralicheniformis strains and 22 genomes from other representative Bacilli [33]. The resulting tree (Fig. 2) shows the phylogenetic proximity of Bac 48 and Bac 84 to $B$. paralicheniformis strains and reveals them to be more distantly related to $B$. licheniformis than previously reported [30].

\section{Exploring the biosynthetic potential of $B$.} paralicheniformis Bac48 and B. paralicheniformis Bac84

To evaluate the biosynthetic potential of the two species (B. licheniformis and $B$. paralicheniformis), nine complete $B$. licheniformis and five complete $B$. paralicheniformis genomes, including the two Red Sea strains, were used (Table 1). 

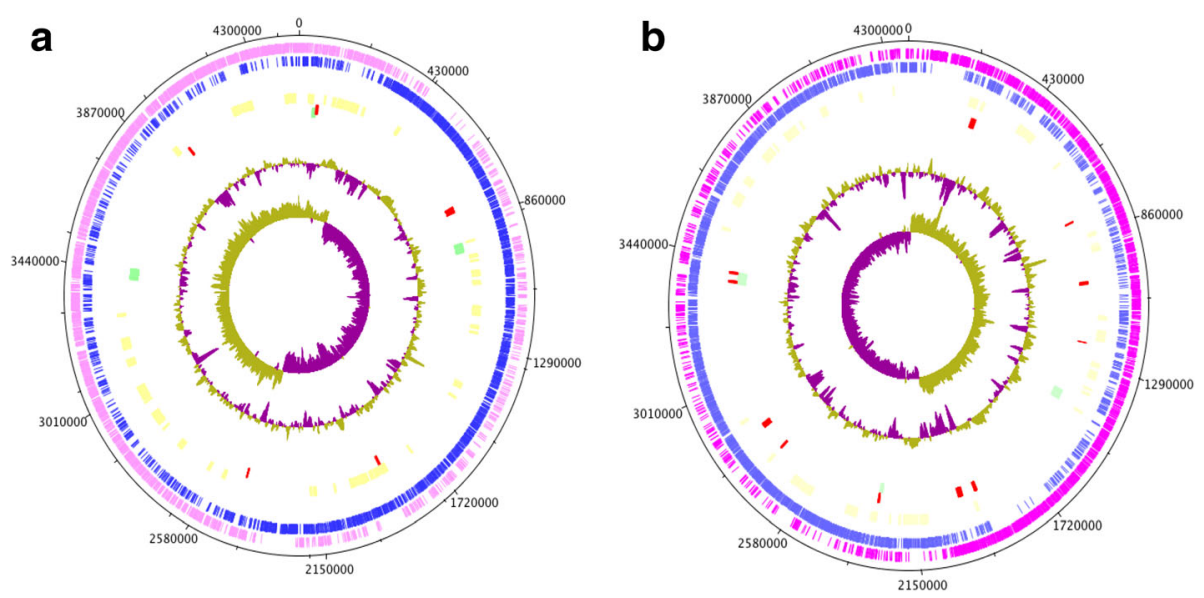

Fig. 1 Circular plots of (a) B. paralicheniformis Bac48 and (b) B. paralicheniformis Bac84 genomes, showing the distribution of genomic islands, prophages and biosynthetic genes in the genomes. The tracks show the following features starting from the outermost track; 1st track (pink): genes on the positive strand; 2nd track (blue): genes on the negative strand; 3rd track (yellow): biosynthetic gene clusters; 4th track (red): horizontally transferred genes; 5th track (green): genes in prophage regions; 6th track: GC-plot where purple and green correspond to below and above average GC content, respectively; 7th track: GC-skew where purple and green correspond to below and above average GC-skew, respectively

On average, each of the analyzed genomes comprised 34 putative biosynthetic gene clusters that were predicted by antiSMASH [24]. These clusters encode peptides/proteins associated with the biosynthesis of one of the following types of secondary metabolites: bacteriocins, lanthipeptides, NRPS, type III PKSs, hybrid PKS/ NRPS clusters and unclassified clusters (Fig. 3). This analysis showed that $B$. paralicheniformis strains have more biosynthetic genes $(\sim 8.5 \%$ of total predicted ORFs) compared to B. licheniformis ( $\sim 6.3 \%$ of total predicted ORFs). In this study, we focus on two types of compounds that are often associated with high antimicrobial activity: $1 /$ modular clusters (NRPS and modular PKS), and $2 /$ ribosomally synthesized peptides, namely modified and unmodified bacteriocins.

A total of 480 BGCs were classified into 54 groups (also referred to as gene cluster families GCFs) using scoring similarity networks as implemented in BiG-SCAPE (Fig. 4) [34]. Interestingly, only 6 GCFs (ca. 11\% of the total) were assigned to clusters that produce known products or have a similar pathway using threshold similarity of $60 \%$ (Additional file 1: Figure S2). This highlights the limited knowledge available for the analyzed strains. Furthermore, these

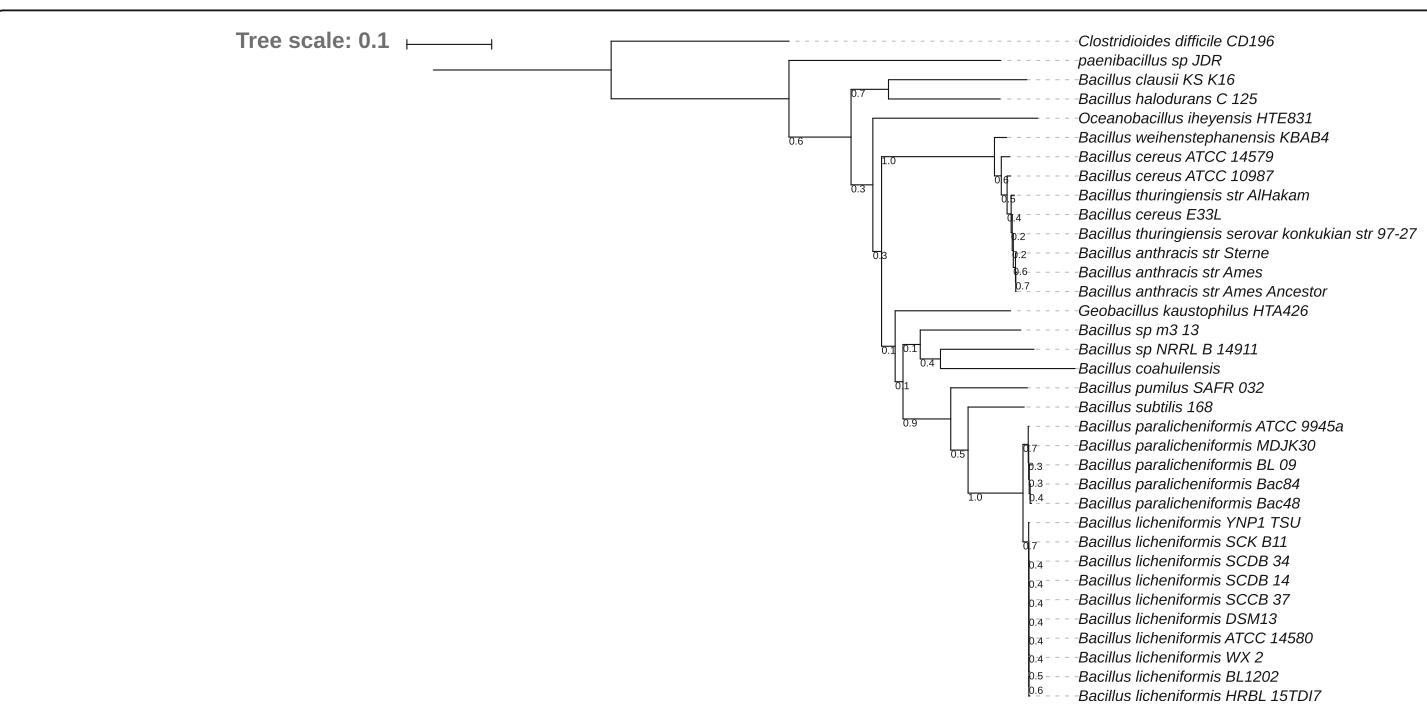

Fig. 2 Maximum-likelihood phylogenetic tree of 35 genomes constructed using 494 orthologous groups. Clostridioides difficile CD196 was used as the outgroup. Bac48 and Bac84 are placed with the B. paralicheniformis subgroup 


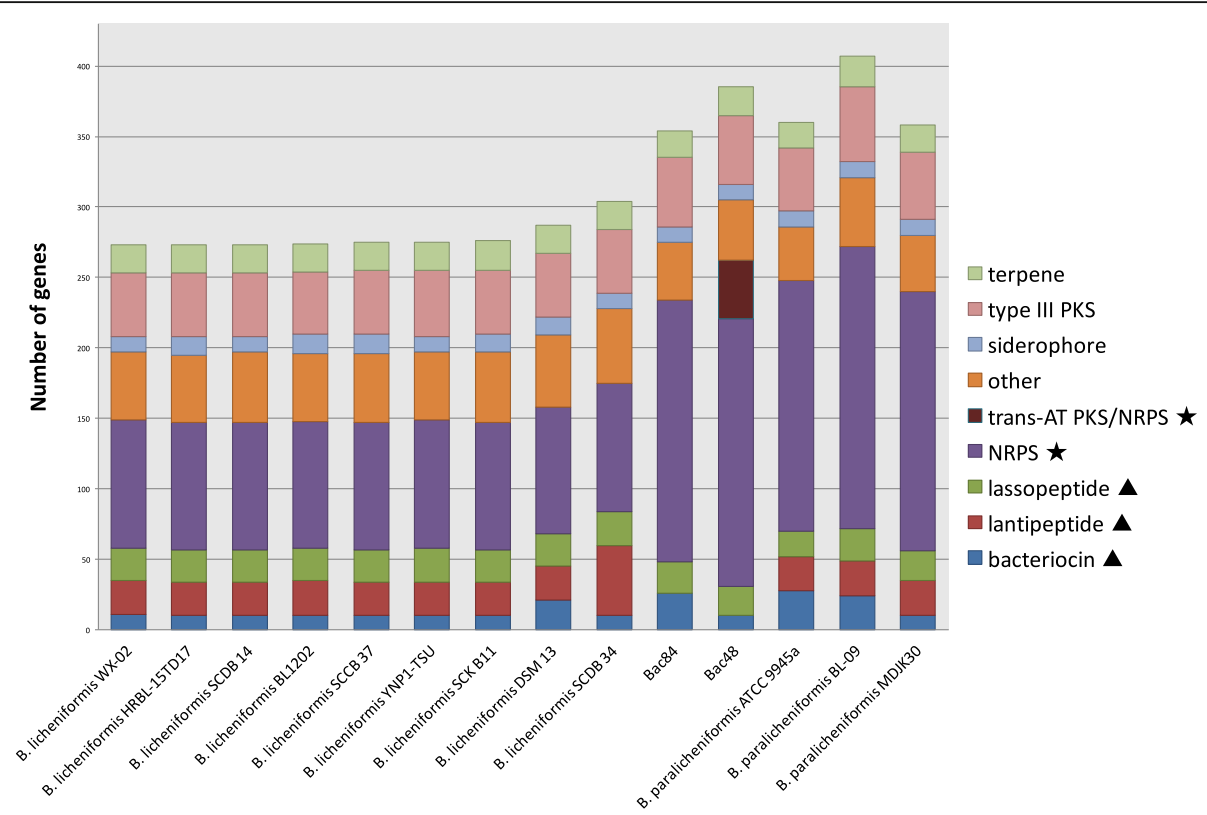

Fig. 3 Distribution of genes in biosynthetic gene clusters in nine B. licheniformis and five B. paralicheniformis genomes. Clusters with modular genes are marked with a star and clusters encoding for ribosomally synthesized peptides are marked with a triangle

unexplored secondary metabolites can potentially provide new antimicrobial agents and compounds of industrial importance, thus warranting future studies of these BGCs to identify their functions.

\section{Nonribosomal peptides and modular polyketides}

Modular genes in NRPS and PKS clusters are of critical importance when assessing the biotechnological value of strains. Understanding the organization of domains in modules could help advance efforts for the synthesis of products with amended physiochemical properties and enhanced bioactivity [35].

The identified NRPS clusters were grouped into four GCFs with predicted products (Fig. 4). The first group, we found to be conserved across all B. licheniformis and B. paralicheniformis strains, has 46 genes on average per genome, and shares $46 \%$ of its genes with the bacillibactin cluster, a siderophore commonly produced in the $\mathrm{Ba}$ cillus genus [36]. The second GCF of NRPS clusters has 43 genes that include the lichenysin operon (licABC), an efficient biosurfactant from the surfactin family [37-39]. The third and fourth NRPS clusters were only detected in the $B$. paralicheniformis strains, including B. paralicheniformis Bac48 and B. paralicheniformis Bac84, with 50 and 45 genes and with 86 and 100\% similarity to the BGC of the antifungal fengycin [40-42] and the narrow-spectrum antibiotic bacitracin [43-46], respectively. In fact, hierarchical clustering shows distinctive presence/absence patterns of BGCs in the two different groups (Fig. 4).
A hybrid PKS/NRPS cluster was identified in the genome of B. paralicheniformis Bac48 (Fig. 5). To the best of our knowledge, this is the first trans-acyltransferase (trans-AT) PKS/NRPS cluster reported in strains of this species. Trans-AT PKS biosynthetic clusters are an emerging class of modular PKSs that are becoming more commonly found in microbial genomes [47]. Structurally, a trans-AT PKS cluster is different from a typical cis-AT PKS in that the AT domain, which loads the substrate onto acyl carrier protein domains (ACPs), is encoded in a separate ORF as independent polypeptide and not integrated into the assembly line [47]. Other trans-AT PKS/NRPS clusters reported within the genus Bacillus is the antibiotic bacillaene pksX cluster found in B. subtilis [48] and the bae operon in B. amyloliquefaciens [48]. The hybrid trans-AT PKS/NRPS cluster is located $14.6 \mathrm{~Kb}$ downstream of a lichenysin synthase operon (licABC). The cluster was predicted as a single BGC along with the lichenysin operon; however, due to the large non-biosynthetic gap between the two clusters, the predicted cluster was split into two. The resultant BGC is composed of 29 genes. The cluster extends over $82.8 \mathrm{~Kb}$, which is close in size to the bacillaene and pks $X$ cluster $(\sim 80 \mathrm{~Kb})$ [49]. One of the architectural differences between this cluster and the other trans-AT PKS clusters in Bacillus is that there is one NRPS module with its domains (adenylation, condensation and peptidyl carrier domains) extended over two ORFs, while on the other hand, the bae cluster has two NRPS modules in two ORFs [49]. 

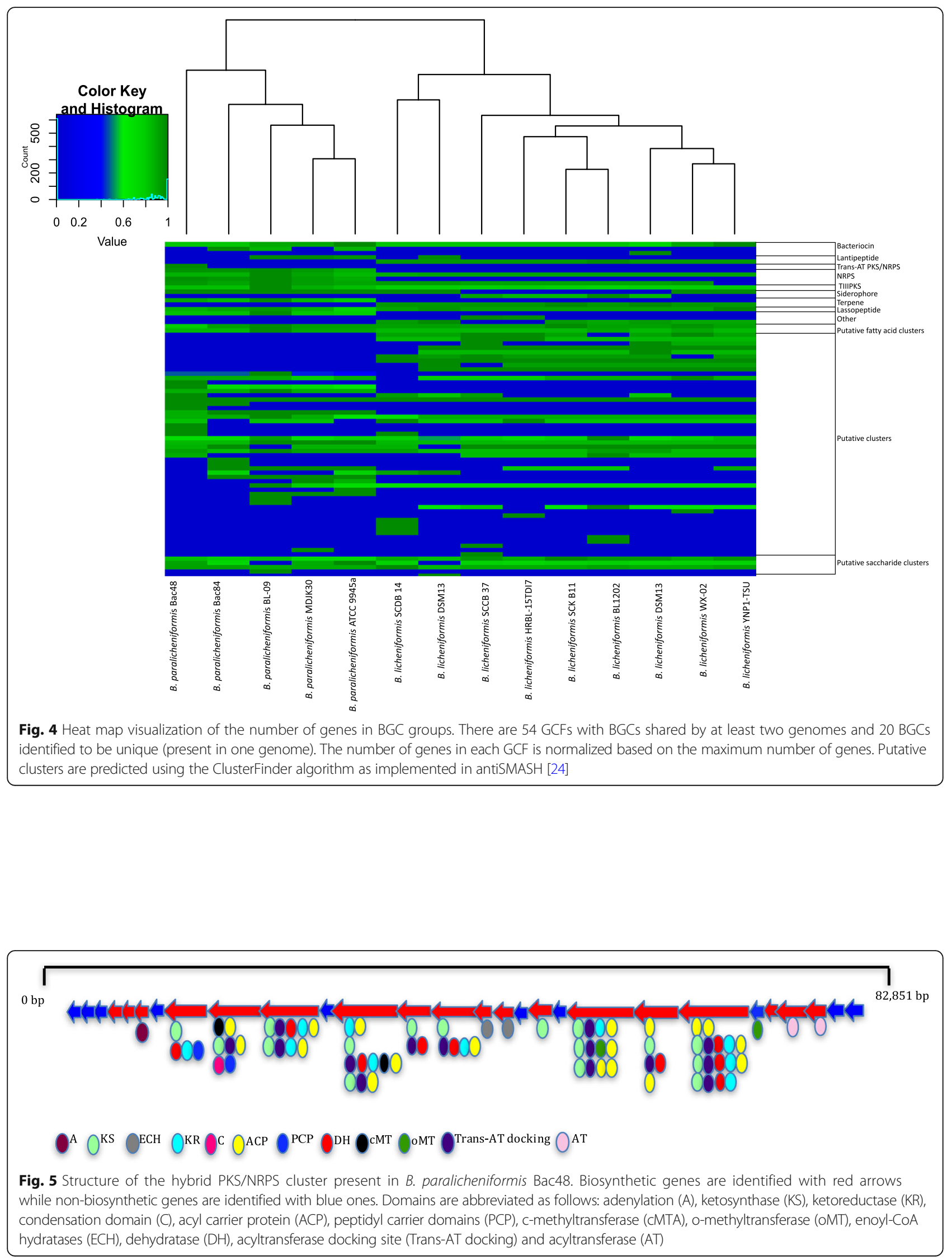
The cluster encodes nine multi-domain ORFs, consisting of one adenylation domain (A), 16 ketosynthase domains (KS), ten ketoreductase domains (KR), two peptidyl carrier domains (PCP), 18 acyl carrier protein domains (ACP), nine dehydratase domains (DH), two enoyl-CoA hydratases domains $(\mathrm{ECH})$, two c-methyltransferase domains (cMT), two o-methyltransferase domains (oMT), and one condensation $(\mathrm{C})$ domain. We also identified truncated AT domains that could be used as binding sites for trans-acting AT. The order of the PKS domains and the absence of integrated AT domains in all of the nine PKS/NRPS ORFs in this gene cluster suggest that this is indeed a trans-AT PKS cluster, with two trans-acting AT domains encoded by ORFs that are independent from the polypeptide assembly line. Moreover, the cluster showed similarity to known trans-AT PKSs (71\% to elansolid and $57 \%$ to thiomarinol) (Additional file 1: Figure S3). Comparing this cluster to known clusters in Bacillus revealed a $57 \%$ similarity to the bacillaene cluster in Bacillus amyloliquefaciens FZB 42. The incomplete homology between the modular genes in this cluster and known clusters in the MIBiG database indicates that the potential active compound synthesized by the trans-AT PKS/NRPS cluster might be a completely novel compound or a compound with similarity in activity to these known compounds. We further identified a putative promoter sequence in the intergenic region upstream of this cluster (Additional file), which strengthens the possible functionality associated with the trans-AT PKS/NRPS cluster.

\section{Ribosomally synthesized peptides and post-translationally modified peptides (RiPPs): Bacteriocins and lanthipeptide}

There is at least one bacteriocin cluster family in each of the analyzed genomes. One of the families was conserved across all the B. licheniformis and B. paralicheniformis strains, with an average of nine genes. The clusters in this group had three biosynthetic genes (ribosomal mythelotransferace accessory protein, carbohydrate esterase and an uncharacterized protein) and showed no similarity to any known bacteriocin. Another head-to-tail bacteriocin cluster family was detected in the genomes of $B$. paralicheniformis strains ATCC 9945a, BL-09 and Bac84. Clusters in this family had mostly uncharacterized genes and showed no evident similarity to any known bacteriocin.

Lanthipeptides are a type of bacteriocins that often contain unusual amino acids such as lanthionine and undergo post-translational modification. The fact that these post-translational modification genes are highly conserved assists in the in silico prediction of lanthipeptide clusters [50]. Other features common to lanthipeptide clusters include immunity genes and $A B C$ transporters for bacteriocin export [51].
We found that two-component class II lanthipeptides, in which two peptides processed by a modifying enzyme $(\operatorname{lanM})$ [52], are the most common lanthipeptides in the analyzed genomes. $B$. licheniformis strains have three genes mapping to $l \operatorname{ch} A 1, l \operatorname{ch} A 2$ and $l \operatorname{ch} M 1$ in the class II lanthipeptide lichenicidin VK21 cluster. The absence of lichenicidin post-translational modification genes in $B$. paralicheniformis is a distinguishing feature between the two species. A lanthipeptide cluster was detected in the B. paralicheniformis genomes (MDJK30, BL-09 and ATCC 9945a), and in B. licheniformis SCDB 34 with a mersacidin-like structural gene. The cluster is predicted to be of class II lanthipeptides as it has the lanM post-translational modification enzyme. However, other mersacidin genes ( $m r s K 2, m r s R 2, m r s F, m r s G$ and $m r s E$ ) were not detected, indicating that the cluster might be involved in the synthesis of a new product with partial genomic similarity to the genes encoding for the antibiotic mersacidin. No lanthipeptide clusters were predicted in the Red Sea strains; however, the genomes of B. paralicheniformis Bac84 harbored a lantibiotic-like cluster, with the subtilin biosynthesis post-translational modification gene $s p a B$ that encodes the dehydratase of the lanthionine in the subtilin gene cluster (PFAM: PF04738) and subtilin ABC transporter permease (spaG). The cluster was not predicted as a lanthipeptide as it lacked other genomic features including the post-translational modification enzyme necessary for the cyclization of lanthionine (spaC in the subtilin cluster) and other immunity genes. Additionally, seven genes in the cluster were similar to genes in the rhizocticin biosynthetic cluster, an unusual peptide with antimicrobial activity.

\section{Discussion}

Alignment of the $B$. paralicheniformis Bac48 and $B$. paralicheniformis Bac84 genomes, showed the two genomes to be highly syntenic, except for three large regions present in the $B$. paralicheniformis Bac48 genome that are absent from the $B$. paralicheniformis Bac84 genome (Additional file 1: Figure S1 A and B). The largest non-syntenic block is $\mathrm{a} \sim 83 \mathrm{~Kb}$ region in which the previously described trans-AT PKS/NRPS cluster resides. More specifically, it is worth noting that the trans-AT PKS/NRPS cluster in B. paralicheniformis Bac48 has a $27.59 \%$ overlap (8 horizontally transferred genes) with a genomic island. Moreover, a bacteriocin cluster composed of 16 genes, has $62.5 \%$ overlap with a genomic island in B. paralicheniformis Bac84 (10 horizontally transferred genes) (Fig. 1). Obtaining such foreign genes can alter the genotype of a strain through the acquisition of novel metabolic capabilities or altering the existing ones. Herewith allowing strains to adapt/survive in different ecosystems (in this instance, mangrove mud as 
opposed to microbial mat) [53-55]. This makes the discovery interesting as we previously reported [30] that these strains exhibit different antimicrobial activity; specifically, B. paralicheniformis Bac84 has stronger antimicrobial potential against three-indicator pathogens: Staphylococcus aureus, Salmonella typhimurium, and Pseudomonas syringae. Thus, the disparity associated with the antimicrobial activity could be a consequence of the foreign genes providing a novel product with antimicrobial activity.

Also, our analysis showed that the number of NRPS clusters (e.g., lipopeptides) with known predicted products significantly outnumber RiPP clusters with known predicted products, as only lichenicidinVK21 was identified in these clusters. This difference is expected as Firmicutes have been one of the most important sources for the discovery of new lipopeptides, especially as lipopeptides are highlighted to be attractive pharmaceutical or/and industrial products. Investigating the functions of genes in RiPPs showed that, although some of their genes are similar to the ones in known clusters, they are incomplete, with genes absent from the clusters in most of the cases, prevents the use of assigned databases such as MIBiG to determine their final products. Genes in RiPPs from other partially sequenced genomes encode known products such as the recently discovered novel lanthipeptide formicin, produced by $B$. paralicheniformis APC 1576 [56], the bacteriocin bacillocin 490 produced by $B$. licheniformis $490 / 5$ [57] and the bacteriocin-like lichen produced by $B$. licheniformis 26 L-10/3RA [58]. However, B. paralicheniformis RiPPs are understudied and the data presented in this in silico analysis highlights the potential for these organisms and the need for further work to validate these findings.

\section{Conclusion}

Several proteins synthesized by B. licheniformis strains have high industrial value and are exploited in many applications. However, the bioactive potential of $B$. paralicheniformis species is not completely explored. Here, we report B. paralicheniformis strains are more enriched with lipopeptide encoding genes compared to $B$. licheniformis strains. Moreover, the two Red Sea strains, B. paralicheniformis Bac48 and B. paralicheniformis Bac84, were shown to be more enriched with gene clusters that biosynthesizes bioactive compounds. In spite of the high synteny between the two genomes, we show that $B$. paralicheniformis Bac48 is more enriched in structurally unique modular PKS clusters compared to $B$. paralicheniformis and $B$. licheniformis strains. In future work, more experimental testing is needed in order to exhaustively examine all potential bioactive compounds and the cause of antimicrobial discrepancy between the two strains.

\section{Method}

Sampling, isolation and purification of bacterial strains The sampling, isolation and purification of strains Bac48 and Bac84 were previously described by Al-Amoudi et al. (2016) [30]. Both strains were isolated from samples collected from the Rabigh Harbor Lagoon by the Red Sea in Saudi Arabia $\left(39^{\circ} 0^{\prime} 35.762^{\prime \prime} \mathrm{E}, 22^{\circ} 45^{\prime} 5.582^{\prime \prime} \mathrm{N}\right)$. Bac48 was isolated from samples that were taken from mangrove mud; while Bac84 was isolated from a microbial mat located $7.5 \mathrm{~m}$ away from the lagoon. Eight grams of each sample were homogenized using $10 \mathrm{~mL}$ of sterilized Red Sea water at low speed. The supernatant was diluted 5 and 25 folds and plated on media prepared with artificial seawater. Microbial culture containing Bac48 was grown on actinomycetes isolation agar; while culture containing Bac84 was grown on Difco Marine broth 2216 gellan gum media. Inoculated plates were incubated at $28{ }^{\circ} \mathrm{C}$ for up to 28 days. Pure colonies were obtained after multiple successful transfers based on morphology then frozen at $-80{ }^{\circ} \mathrm{C}$ in $\mathrm{ddH}_{2} \mathrm{O}$ for DNA extraction and $30 \%$ glycerol solution for long-term storage.

\section{DNA extraction and sequencing}

Biomass of B. paralicheniformis Bac48 and B. paralicheniformis Bac84 was obtained after growth under optimal conditions [30]. Genomic DNA was extracted using the Sigma's GenElute Bacterial Genomic DNA Kit (USA) following the manufacturer's protocol followed by a second purification step using $\mathrm{MO} \mathrm{BIO}$ PowerClean Pro Clean-Up Kit (USA). As quality control measures, overnight gel electrophoresis and NanoDrop (Thermo Fisher Scientific, USA) were used to assess purity of DNA, while Qubit 2.0 (Life Technologies, Germany) was used to quantify the DNA. Whole genome sequencing was performed at the Core Lab sequencing facility at KAUST using the PacBio RS II sequencing platform (Pacific Biosciences, USA). The large-insert libraries were sequenced in single-molecule real-time (SMRT) sequencing cells using P6-C4 chemistry.

\section{Genome assembly}

Raw data from PacBio's RS II were assembled using PacBio's SMRT Analysis pipeline v2.3.0. using default parameters and genomeSize of $6,000,000 \mathrm{bp}$, which produced a single contig per library. We visually checked for overlapping ends using Gepard v1.40 [59] which would indicate circular genomes. To circularize both genomes, one end of each contig was trimmed to reduce the amount of overlap, then each contig was split into two halves which were then rejoined using minimus2 [60]. After circularization, multiple rounds of assembly polishing were performed using the SMRT Analysis Resequencing protocol until convergence (Additional file). To assess the quality of the genomes 
and estimate their completeness and contamination, checkM v1.0.6 [61] taxonomic workflow was used, utilizing single copy genes in the genus Bacillus.

\section{Genome functional annotation and analysis}

The complete genome sequences for $B$. paralicheniformis Bac48 and B. paralicheniformis Bac84 were annotated using the Automatic Annotation of Microbial Genomes pipeline (AAMG) [62] with default parameters (BLAST bit score of 30) and Prodigal [63] as the chosen gene predictor. For details about the annotation pipeline, tools and databases used, refer to [62].

The overall genome similarities between $B$. paralicheniformis Bac48 and B. paralicheniformis Bac84 were inspected using a dot plot that was generated with Gepard v1.40 [59]. Genome variation and synteny were inspected between the two strains using Sibelia v3.0.6 [64]. Prediction of genomic islands was done using IslandViewer v3 [65] and the identification of phage inserts was performed using PHASTER [66]. Finally, circular visualization of the genomes and annotated features were plotted using DNAPlotter [67].

\section{Strain identification and phylogeny}

To build the phylogeny tree, orthologous protein groups (orthogroups) were obtained using OrthoFinder v2.2.1 [68] with default settings. Briefly, an all-vs-all BLASTp analysis [69] was initially performed for the preliminary assignment of gene pairs. Gene pairs were then filtered based on the length-normalized BLAST bitscores to generate a gene pair graph for all-vs-all species. Next, orthogroups were inferred from the graph using the MCL tool v14.137 [70]. After establishing orthology, gene trees were constructed for all orthogroups in the core genomes (all species present) using the alignment-free tool DendroBlast [71] and FastMe v2.1.10 [72]. The Species tree was then reconstructed with support values from the consensus of all gene trees using STAG v1.0.0 (https://github.com/davidemms/STAG) and rooted based on duplication events using STRIDE v1.0.0 [https://doi.org/10.1093/molbev/msx259]. We visualized the tree using iTOL (https://itol.embl.de/) [68].

\section{Biosynthetic gene cluster prediction}

Only published strains with complete genomes were included in the analysis to ensure that the identified variations were indeed due to functional differences and not due to the quality of assembly. At the time of our study (May 2017) 12 strains satisfied these requirements, nine B. licheniformis and three B. paralicheniformis. To avoid potential bias resulting from using different annotation pipelines, all strains were reannotated using the same set of tools and databases.
Biosynthetic and secondary metabolic gene clusters were predicted using antiSMASH v3.0 [24] with the ClusterFinder option [23]. Additionally, the KnownClusterBlast option was used to identify potential products for the clusters from the MIBiG database. Each BLAST hit for the 54 GCFs were manually checked to ensure the similarity accounts for the core biosynthetic genes in the cluster. The promoter prediction tool provided by Softberry [73] was used to predict promoter sequences in the intergenic region upstream of predicted BGCs in the genomes of B. paralicheniformis Bac48 and B. paralicheniformis Bac84.

\section{Additional file}

Additional file 1: Table S1. Basic statistics relating to the PacBio SMRT sequencing that was done for B. paralicheniformis B48 and B84. A single SMRT cell was sequenced for each strain. Table S2. Levels of completeness and contamination in Bac48 and Bac84 as determined in CheckM. Figure S1. Similarity between the genomes of $B$. paralicheniformis Bac48 and B. paralicheniformis Bac84. A) Circos figure showing synteny blocks between B. paralicheniformis Bac48 and B. paralicheniformis Bac84. Table S3. List of genomic island regions in the genomes of $B$. paralicheniformis Bac48 and B. paralicheniformis Bac84, predicted using IslandViewer [4]. Table S4. Predicted prophage regions in B. paralicheniformis Bac48 and B. paralicheniformis Bac84 and their overlap with Gls. Scores were obtained using PHASTER [5] scoring scheme. Most Common Phage shows the phage ID(s) with the highest number of proteins most similar to proteins in the region. Overlap percentage show the length of overlap region with respect to the length of prophage. Figure S2. Similarity network showing 54 groups of similar BGCs. Strains are color coded as per the legend. A product is assigned - shown on top of each group of nodes- if the clusters in the group share more than $60 \%$ similarity to the product. Similar gene clusters from different genomes were classified into groups based on homology using BiG-SCAPE [33] and visualized using Cytoscape [6]. (DOCX $4336 \mathrm{~kb}$ )

\section{Abbreviations}

A: Adenylation; ACP: Acyl carrier protein; aroE: Shikimate-5-dehydrogenase; AT: Acyltransferase; BGC: Biosynthetic gene cluster; C: Condensation; CMT: c-methyltransferase domains; DH: Dehydratase; ECH: Enoyl-CoA hydratase; GCF: Gene cluster family; gryB: Gyrase subunit B;

KR: Ketoreductase; KS: Ketosynthase; NRPS: Nonribosomal peptide synthetase; OMT: o-methyltransferase; PCP: Peptidyl carrier protein; PKS: Polyketide synthase; RiPP: Ribosomally synthesized and posttranslationally modified peptide; SMRT: Single molecule real-time

\section{Acknowledgments}

The authors wish to acknowledge the experimental support from the King Abdullah University of Science and Technology (KAUST) Bioscience Core Laboratory.

\section{Funding}

The research reported in this publication was supported by King Abdullah University of Science and Technology (KAUST) through the Awards Nos. FCC/1/1976-02-01, FCS/1/2911-01-01, BAS/1/1606-01-01, URF/1/1976-06-01, BAS/1/1624-01-01, BAS/1/1659-01-01, BAS/1/1059-01-01 from the Office of Sponsored Research (OSR).

Availability of data and materials

All data used in this study have been included in this article and its Additiona files.

Authors' contributions

The study was conceived and designed by GO, IM, VBB, and ME. Data was generated by GO, AB, SA, HH, and FFL. Data analysis was performed by GO, 
$S B, R R$, and ME. Discussion of analyzed data was provided by $X G, R H, S T A$, TG and IM. The manuscript was written by GO, SB, VBB, AA, and ME. All authors read and approved the final version of the manuscript.

\section{Ethics approval and consent to participate}

Samples were collect as previously reported in [30] by KAUST.

\section{Competing interests}

The authors declare that they have no competing interests.

\section{Publisher's Note}

Springer Nature remains neutral with regard to jurisdictional claims in published maps and institutional affiliations.

\section{Author details}

${ }^{1}$ Computational Bioscience Research Center (CBRC), King Abdullah University of Science and Technology (KAUST), Thuwal 23955-6900, Kingdom of Saudi Arabia. ${ }^{2}$ Biological and Environmental Sciences and Engineering Division (BESE), King Abdullah University of Science and Technology (KAUST), Thuwal 23955-6900, Kingdom of Saudi Arabia. ${ }^{3}$ Department of Biology, Science and Arts College, King Abdulaziz University, Rabigh 21589, Kingdom of Saudi Arabia. ${ }^{4}$ Biology Department, Edge Hill University, L39 4QP, Ormskirk, Lancashire, UK. ${ }^{5}$ Department of Biology and Biological Engineering, Division of Systems \& Synthetic Biology, Chalmers University of Technology, Kemivägen 10, 41296 Gothenburg, Sweden. ${ }^{6}$ Novo Nordisk Foundation Center for Biosustainability, Technical University of Denmark, 2800 Lyngby, Denmark. ${ }^{7}$ Department of Medical Laboratories, Faculty of Health Sciences, American University of Madaba, PO Box 2882, Madaba, Amman JO-11821, Jordan.

Received: 28 January 2018 Accepted: 14 May 2018

Published online: 22 May 2018

\section{References}

1. Clements LD, Miller BS, Streips UN. Comparative growth analysis of the facultative anaerobes Bacillus subtilis, Bacillus licheniformis, and Escherichia coli. Syst Appl Microbiol. 2002;25(2):284-6.

2. Veith B, Herzberg C, Steckel S, Feesche J, Maurer KH, Ehrenreich P, Baumer $\mathrm{S}$, Henne A, Liesegang $\mathrm{H}$, Merkl R, et al. The complete genome sequence of Bacillus licheniformis DSM13, an organism with great industrial potential. J Mol Microbiol Biotechnol. 2004;7(4):204-11.

3. Rey MW, Ramaiya P, Nelson BA, Brody-Karpin SD, Zaretsky EJ, Tang M, de Leon AL, Xiang H, Gusti V, Clausen IG. Complete genome sequence of the industrial bacterium Bacillus licheniformis and comparisons with closely related Bacillus species. Genome Biol. 2004;5(10):r77.

4. Fujinami S, Fujisawa M. Industrial applications of alkaliphiles and their enzymes-past, present and future. Environ Technol. 2010;31(8-9):845-56.

5. Gosset G. Microbial production of industrial chemicals. Introduction. J Mol Microbiol Biotechnol. 2008;15(1):5-7.

6. Erickson R. Industrial applications of the bacilli: a review and prospectus: Microbiology American Society for Microbiology, Washington, DC; 1976. p. 406-19.

7. De Almeida DG, Rita de Cássia F, JML S, Rufino RD, Santos VA, Banat IM, Sarubbo LA. Biosurfactants: promising molecules for petroleum biotechnology advances. Front Microbiol. 2016;7

8. Das P, Mukherjee S, Sen R. Antimicrobial potential of a lipopeptide biosurfactant derived from a marine Bacillus circulans. J Appl Microbiol. 2008;104(6):1675-84

9. Perez KJ, dos Santos VJ, Lopes FC, Pereira JQ, dos Santos DM, Oliveira JS, Velho RV, Crispim SM, Nicoli JR, Brandelli A. Bacillus spp. isolated from puba as a source of biosurfactants and antimicrobial lipopeptides. Front Microbiol. 2017:8.

10. Gomaa EZ. Antimicrobial activity of a biosurfactant produced by Bacillus licheniformis strain M104 grown on whey. Braz Arch Biol Technol. 2013; 56(2):259-68.

11. El-Sheshtawy H, Aiad I, Osman M, Abo-ELnasr A, Kobisy A. Production of biosurfactant from Bacillus licheniformis for microbial enhanced oil recovery and inhibition the growth of sulfate reducing bacteria. Egypt J Pet. 2015; 24(2):155-62.
12. Bouizgarne B. Bacteria for plant growth promotion and disease management. In: Bacteria in agrobiology: disease management. Berlin: Springer; 2013. p. 15-47.

13. Neyra C, Atkinson L, Olubayi O, Sadasivan L, Zaurov D, Zappi E. Novel microbial technologies for the enhancement of plant growth and biocontrol of fungal diseases in crops. Cahiers Opt Méd. 1996:31:447-56.

14. Lee JP, Lee S-W, Kim CS, Son JH, Song JH, Lee KY, Kim HJ, Jung SJ, Moon BJ. Evaluation of formulations of Bacillus licheniformis for the biological control of tomato gray mold caused by Botrytis cinerea. Biol Control. 2006; 37(3):329-37.

15. Kim JH, Lee SH, Kim CS, Lim EK, Choi KH, Kong HG, Kim DW, Lee SW, Moon BJ. Biological control of strawberry gray mold caused by Botrytis cinerea using Bacillus licheniformis N1 formulation. J Microbiol Biotechnol. 2007; 17(3):438-44.

16. Joshi SJ, Al-Wahaibi YM, Al-Bahry SN, Elshafie AE, Al-Bemani AS, Al-Bahri A Al-Mandhari MS. Production, characterization, and application of Bacillus licheniformis W16 biosurfactant in enhancing oil recovery. Front Microbiol. 2016;7

17. Dunlap CA, Kwon SW, Rooney AP, Kim SJ. Bacillus paralicheniformis sp. nov isolated from fermented soybean paste. Int I Syst Evol Microbiol. 2015; 65(10):3487-92.

18. Dhakal R, Chauhan K, Seale RB, Deeth HC, Pillidge CJ, Powell IB, Craven H, Turner MS. Genotyping of dairy Bacillus licheniformis isolates by high resolution melt analysis of multiple variable number tandem repeat loci. Food Microbiol. 2013;34(2):344-51.

19. Hoffmann K, Daum G, Koster M, Kulicke WM, Meyer-Rammes H, Bisping B, Meinhardt F. Genetic improvement of Bacillus licheniformis strains for efficient deproteinization of shrimp shells and production of high-molecularmass chitin and chitosan. Appl Environ Microbiol. 2010;76(24):8211-21.

20. Cai D, He P, Lu X, Zhu C, Zhu J, Zhan Y, Wang Q, Wen Z, Chen S. A novel approach to improve poly-gamma-glutamic acid production by NADPH regeneration in Bacillus licheniformis WX-02. Sci Rep. 2017;7:43404.

21. Qiu Y, Zhang J, Li L, Wen Z, Nomura CT, Wu S, Chen S. Engineering Bacillus licheniformis for the production of meso-2,3-butanediol. Biotechnol Biofuels. 2016;9:117.

22. Borgmeier C, Bongaerts J, Meinhardt F. Genetic analysis of the Bacillus licheniformis degSU operon and the impact of regulatory mutations on protease production. J Biotechnol. 2012;159(1-2):12-20.

23. Cimermancic P, Medema MH, Claesen J, Kurita K, Brown LCW, Mavrommatis K, Pati A, Godfrey PA, Koehrsen M, Clardy J. Insights into secondary metabolism from a global analysis of prokaryotic biosynthetic gene clusters. Cell. 2014;158(2):412-21.

24. Weber T, Blin K, Duddela S, Krug D, Kim HU, Bruccoleri R, Lee SY, Fischbach MA, Müller R, Wohlleben W. antiSMASH 3.0-a comprehensive resource for the genome mining of biosynthetic gene clusters. Nucleic Acids Res. 2015; 43(W1):W237-43.

25. Underwood SA, Buszko ML, Shanmugam KT, Ingram LO. Lack of protective osmolytes limits final cell density and volumetric productivity of ethanologenic Escherichia coli KO11 during xylose fermentation. App Environ Microbiol. 2004;70(5):2734-40.

26. Schwalbach MS, Keating DH, Tremaine M, Marner WD, Zhang Y, Bothfeld W, Higbee A, Grass JA, Cotten C, Reed JL, et al. Complex physiology and compound stress responses during fermentation of alkali-pretreated corn Stover hydrolysate by an Escherichia coli ethanologen. Appl Environ Microbiol. 2012;78(9):3442-57.

27. Schroeter R, Hoffmann T, Voigt B, Meyer H, Bleisteiner M, Muntel J, Jurgen B, Albrecht $D$, Becher $D$, Lalk $M$, et al. Stress responses of the industrial workhorse Bacillus licheniformis to osmotic challenges. PLoS One. 2013;8(11):e80956.

28. Ngugi DK, Antunes A, Brune A, Stingl U. Biogeography of pelagic bacterioplankton across an antagonistic temperature-salinity gradient in the Red Sea. Mol Ecol. 2012;21 (2):388-405.

29. Nielsen J, Archer J, Essack M, Bajic VB, Gojobori T, Mijakovic I. Building a biobased industry in the Middle East through harnessing the potential of the Red Sea biodiversity. Appl Microbiol Biotechnol. 2017;101(12):4837-51.

30. Al-Amoudi S, Essack M, Simões MF, Bougouffa S, Soloviev I, Archer JA, Lafi FF, Bajic VB. Bioprospecting Red Sea coastal ecosystems for Culturable microorganisms and their antimicrobial potential. Marine Drugs. 2016;14(9):165.

31. Posfai G, Plunkett G 3rd, Feher T, Frisch D, Keil GM, Umenhoffer K, Kolisnychenko V, Stahl B, Sharma SS, de Arruda M, et al. Emergent properties of reduced-genome Escherichia coli. Science. 2006;312(5776): 1044-6. 
32. Wang A, Ash GJ. Whole genome phylogeny of Bacillus by feature frequency profiles (FFP). Sci Rep. 2015;5:13644.

33. Alcaraz LD, Moreno-Hagelsieb G, Eguiarte LE, Souza V, Herrera-Estrella L, Olmedo G. Understanding the evolutionary relationships and major traits of Bacillus through comparative genomics. BMC Genomics. 2010;11(1):332.

34. Yeong M: BiG-SCAPE: exploring biosynthetic diversity through gene cluster similarity networks; 2016.

35. Kim E, Moore BS, Yoon YJ. Reinvigorating natural product combinatorial biosynthesis with synthetic biology. Nat Chem Biol. 2015;11(9):649-59.

36. May JJ, Wendrich TM, Marahiel MA. The dhb operon of Bacillus subtilis encodes the biosynthetic template for the catecholic siderophore 2,3dihydroxybenzoate-glycine-threonine trimeric ester bacillibactin. J Biol Chem. 2001;276(10):7209-17.

37. Madslien EH, Ronning HT, Lindback T, Hassel B, Andersson MA, Granum PE. Lichenysin is produced by most Bacillus licheniformis strains. J Appl Microbiol. 2013;115(4):1068-80

38. Grangemard I, Wallach J, Maget-Dana R, Peypoux F. Lichenysin: a more efficient cation chelator than surfactin. Appl Biochem Biotechnol. 2001;90(3): 199-210.

39. Nerurkar AS. Structural and molecular characteristics of lichenysin and its relationship with surface activity. Adv Exp Med Biol. 2010;672:304-15.

40. Ongena $M$, Jacques $P$, Touré $Y$, Destain J, Jabrane $A$, Thonart $P$. Involvement of fengycin-type lipopeptides in the multifaceted biocontrol potential of Bacillus subtilis. Appl Microbiol Biotechnol. 2005;69(1):29.

41. Romero D, de Vicente A, Rakotoaly RH, Dufour SE, Veening J-W, Arrebola E, Cazorla FM, Kuipers OP, Paquot M, Pérez-García A. The iturin and fengycin families of lipopeptides are key factors in antagonism of Bacillus subtilis toward Podosphaera fusca. Mol Plant-Microbe Interact. 2007;20(4):430-40.

42. Vanittanakom N, Loeffler W, Koch U, Jung G. Fengycin-a novel antifungal lipopeptide antibiotic produced by Bacillus subtilis F-29-3. J Antibiot. 1986 39(7):888-901.

43. Konz D, Klens A, Schörgendorfer K, Marahiel MA. The bacitracin biosynthesis operon of Bacillus licheniformis ATCC 10716: molecular characterization of three multi-modular peptide synthetases. Chem Biol. 1997:4(12):927-37.

44. Johnson BA, Anker H, Meleney FL. Bacitracin: a new antibiotic produced by a member of the B. Subtilis group. Science. 1945;102(2650):376-7.

45. Alvarez-Ordonez A, Begley M, Clifford T, Deasy T, Considine K, O'Connor P, Ross RP, Hill C. Investigation of the antimicrobial activity of Bacillus licheniformis strains isolated from retail powdered infant milk formulae. Probiotics Antimicrob Proteins. 2014;6(1):32-40.

46. Meleney FL, Altemeier WA, Longacre AB, Pulaski EJ, Zintel HA. The results of the systemic administration of the antibiotic, bacitracin, in surgical infections: a preliminary report. Ann Surg. 1948;128(4):714.

47. Gay DC, Gay G, Axelrod AJ, Jenner M, Kohlhaas C, Kampa A, Oldham NJ, Piel J, Keatinge-Clay AT. A close look at a ketosynthase from a transacyltransferase modular polyketide synthase. Structure. 2014;22(3):444-51.

48. Albertini AM, Caramori T, Scoffone F, Scotti C, Galizzi A. Sequence around the $159^{\circ}$ region of the Bacillus subtilis genome: the pks $X$ locus spans 33.6 kb. Microbiology. 1995;141(2):299-309.

49. Chen XH, Vater J, Piel J, Franke P, Scholz R, Schneider K, Koumoutsi A, Hitzeroth G, Grammel N, Strittmatter AW, et al. Structural and functional characterization of three polyketide synthase gene clusters in Bacillus amyloliquefaciens FZB 42. J Bacteriol. 2006;188(11):4024-36.

50. Walsh CJ, Guinane CM, Hill C, Ross RP, OToole PW, Cotter PD. In silico identification of bacteriocin gene clusters in the gastrointestinal tract, based on the human microbiome Project's reference genome database. BMC Microbiol. 2015:15(1):183

51. Lee H, Kim HY. Lantibiotics, class I bacteriocins from the genus Bacillus. J Microbiol Biotechnol. 2011:21(3):229-35.

52. Willey JM, van der Donk WA. Lantibiotics: peptides of diverse structure and function. Annu Rev Microbiol. 2007;61:477-501.

53. Gogarten JP, Doolittle WF, Lawrence JG. Prokaryotic evolution in light of gene transfer. Mol Biol Evol. 2002;19(12):2226-38.

54. Hacker J, Kaper JB. Pathogenicity islands and the evolution of microbes. Annu Rev Microbiol. 2000;54:641-79.

55. Lawrence JG. Gene transfer, speciation, and the evolution of bacterial genomes. Curr Opin Microbiol. 1999;2(5):519-23.

56. Collins FW, O'Connor PM, O'Sullivan O, Rea MC, Hill C, Ross RP. Formicin-a novel broad-spectrum two-component lantibiotic produced by Bacillus paralicheniformis APC 1576. Microbiology. 2016;162(9):1662-71.
57. Martirani L, Varcamonti M, Naclerio G, De Felice M. Purification and partial characterization of bacillocin 490, a novel bacteriocin produced by a thermophilic strain of Bacillus licheniformi s. Microb Cell Factories. 2002; $1(1): 1$.

58. Pattnaik $\mathrm{P}$, Grover S, Batish VK. Effect of environmental factors on production of lichenin, a chromosomally encoded bacteriocin-like compound produced by Bacillus licheniformis 26L-10/3RA. Microbiol Res. 2005;160(2):213-8.

59. Krumsiek J, Arnold R, Rattei T. Gepard: a rapid and sensitive tool for creating dotplots on genome scale. Bioinformatics. 2007;23(8):1026-8.

60. Sommer DD, Delcher AL, Salzberg SL, Pop M. Minimus: a fast, lightweight genome assembler. BMC Bioinformatics. 2007;8(1):64

61. Parks DH, Imelfort M, Skennerton CT, Hugenholtz P, Tyson GW. CheckM: assessing the quality of microbial genomes recovered from isolates, single cells, and metagenomes. Genome Res. 2015;25(7):1043-55.

62. Alam I, Antunes A, Kamau AA, Kalkatawi M, Stingl U, Bajic VB. INDIGOINtegrated data warehouse of Mlcrobial GenOmes with examples from the red sea extremophiles. PLoS One. 2013;8(12):e82210.

63. Hyatt D, Chen G-L, LoCascio PF, Land ML, Larimer FW, Hauser LJ. Prodigal: prokaryotic gene recognition and translation initiation site identification. BMC bioinformatics. 2010;11(1):119.

64. Minkin I, Patel A, Kolmogorov M, Vyahhi N, Pham S. Sibelia: a scalable and comprehensive synteny block generation tool for closely related microbial genomes. In: International Workshop on Algorithms in Bioinformatics: 2013. Berlin: Springer; 2013. p. 215-29.

65. Langille MG, Brinkman FS. IslandViewer: an integrated interface for computational identification and visualization of genomic islands. Bioinformatics. 2009;25(5):664-5.

66. Arndt D, Grant JR, Marcu A, Sajed T, Pon A, Liang Y, Wishart DS. PHASTER: a better, faster version of the PHAST phage search tool. Nucleic Acids Res. 2016;44(W1):W16-21.

67. Carver T, Thomson N, Bleasby A, Berriman M, Parkhill J. DNAPlotter: circular and linear interactive genome visualization. Bioinformatics. 2008:25(1):119-20.

68. Letunic I, Bork P. Interactive tree of life (iTOL) v3: an online tool for the display and annotation of phylogenetic and other trees. Nucleic Acids Res. 2016;44(W1):W242-5

69. Altschul SF, Gish W, Miller W, Myers EW, Lipman DJ. Basic local alignment search tool. J Mol Biol. 1990;215(3):403-10.

70. Li L, Stoeckert CJ Jr, Roos DS. OrthoMCL: identification of ortholog groups for eukaryotic genomes. Genome Res. 2003;13(9):2178-89.

71. Kelly S, Maini PK. DendroBLAST: approximate phylogenetic trees in the absence of multiple sequence alignments. PLoS One. 2013;8(3):e58537.

72. Lefort V, Desper R, Gascuel O. FastME 2.0: a comprehensive, accurate, and fast distance-based phylogeny inference program. Mol Biol Evol. 2015; 32(10):2798-800

73. Umarov RK, Solovyev W. Recognition of prokaryotic and eukaryotic promoters using convolutional deep learning neural networks. PLoS One. 2017:12(2):e0171410.

74. Yangtse W, Zhou Y, Lei Y, Qiu Y, Wei X, Ji Z, Qi G, Yong Y, Chen L, Chen S. Genome sequence of Bacillus licheniformis WX-02. J Bacteriol. 2012;194(13): 3561-2.

75. O'Hair JA, Li H, Thapa S, Scholz MB, Zhou S. Draft Genome Sequence of Bacillus licheniformis Strain YNP1-TSU Isolated from Whiterock Springs in Yellowstone National Park. Genome Announc. 2017;5(9):e01496-16.

76. Rachinger M, Volland S, Meinhardt F, Daniel R, Liesegang H. First Insights into the Completely Annotated Genome Sequence of Bacillus licheniformis Strain 9945A. Genome Announc. 2013;1(4):e00525-13. 